\title{
MODELING AND SIMULATION OF 1.8 KW GRID-CONNECTED PHOTOVOLTAIC SYSTEM USING MATLAB
}

\author{
MOHAMMAD ISLAMMUDDIN, NURHAZWANI ANANG AND WAN MARIAM WAN \\ MUDA*
}

Faculty of Ocean Engineering Technology and Informatics, Universiti Malaysia Terengganu, 21030 Kuala Nerus, Terengganu, Malaysia.

*Corresponding author: w.mariam@umt.edu.my

http://doi.org/10.46754/umtjur.2021.10.002

\begin{abstract}
A maximum power point tracking (MPPT) DC/DC converter for a photovoltaic (PV) system is an important component in a PV system. The converter is used to convert the value of DC voltage produced by PV panels to a value accepted by the inverter for on-grid, or battery for off-grid system. In addition, the MPPT is used to extract and maintain the solar PV to its maximum power in all conditions. However, the values of components used in literature of MPPT DC/DC converter for a specific PV module cannot be applied for different capacity. Although sets of equations are given in literature to determine the values of inductor and capacitor used in the circuit, the calculated values do not produce the desired output in most cases because of unclear explanation. The validation of input parameters of the converter is also not properly presented for different solar irradiance and temperature. The efficiency of the converter is still low. Hence, this paper presents step-by-step process on how to design a MPPT DC/DC boost converter in MATLAB/Simulink environment. The incremental conductance method is used as MPPT algorithm to control the duty cycle of the converter. Then, a thorough analysis is done by simulating the developed model under different solar irradiance and temperature. Simulation results are then compared with the theoretical values from $\mathrm{I}-\mathrm{V}$ and P-V curves of the selected PV modules. The results show that the proposed MPPT DC/DC converter is able to extract maximum power from PV modules and the output power produced by the converter also indicates that the converter has a high efficiency at $99.7 \%$ in all selected values of solar irradiance and temperature.
\end{abstract}

Keywords: PV system, MATLAB/simulink, MPPT, DC/DC boost converter, incremental conductance method.

\section{Introduction}

Among the renewable energy (RE) sources, solar energy has become the world's fastest growing energy technology due to factors such as the PV system utilizing the most abundant $\mathrm{RE}$ resource on the planet, i.e. the sun, low maintenance, low solar PV prices compared to other RE technology (Kusch-Brandt, 2019) and can be mounted on a small or large scale. Unlike large-scale PV plants, small-scale PV systems offer solar potential assessments in urban areas, do not cost land and reduce transmission and distribution costs. Therefore, increasing the number of installations of this system is important and related research has been growing in the literature.
To understand the behavior and dynamic characteristics of the PV system, mathematical models are widely used in the literature using MATLAB/Simulink software to model components in the PV system and vary the input parameters to the PV modules to observe the output of the system (Al-Shamani et al., 2017; Al-Waeli et al., 2018; Bellia et al., 2014; Krismadinata et al., 2013) the techno-economic assessment of a Grid-Connected Photovoltaic Thermal (GCPVT. A grid-connected PV system (Huang et al., 2017) consists of PV modules, MPPT DC/DC converter and inverter to convert the DC into AC signal compatible to the grid standard. Whereas, in the off-grid system (Ghafoor \& Munir, 2015) Pakistan $\left(31.42^{\circ} \mathrm{N}\right.$, $73.08^{\circ} \mathrm{E}, 184 \mathrm{~m}$, the battery is used to interface 
between MPPT DC/DC converter and inverter, to store the energy from PV modules and is also as a power supply to a DC load. The MPPT $\mathrm{DC} / \mathrm{DC}$ converter is a key component to ensure the PV modules operate at maximum point in all weather conditions, thus increasing the efficiency of the PV system.

A number of researchers have studied the models of MPPT DC/DC converter in the literature. The research on these components can be categorized into two, first they focus on the design of the converter (Mohamed et al., 2016; Raj et al., 2020; S.Sheik \& Devaraj, 2014; Sahu et al., 2016) daily available, and environment friendly renewable energy source. All PV modules provided in markets gives 12 or $24 \mathrm{~V}$ ( 2 up to $5 \mathrm{~A}$ and second, they improve MPPT techniques (Ahmed \& Salam, 2015; Alik \& Jusoh, 2018; Loukriz et al., 2016; Tey \& Mekhilef, 2014). To design the converter, it involves determination of inductor and capacitor values used in the circuit. Different equations were used in literature and the performance of the system is measured by efficiency. Meanwhile, research that focus on improving MPPT techniques cater to the problems in transient analysis such as overshoot, ripples, and response time during drastic changes in solar irradiance or temperature. Among the MPPT techniques proposed in the literature, the incremental conductance (IncCond) is complex but more efficient compared to the most popular and simple method, Perturb and Observe (Jain et al., 2018).

From the literature, there is room for improvement in designing the MPPT DC/ DC converter, especially on the validation and efficiency of the system. Mohamed et al. (2016) and Sahu et al. proposed a MPPT DC/ DC boost converter, but the validation of the developed models for different solar irradiance and temperature were not done, and they only focus on the improvement of transient states using PI and fuzzy logic controllers (Mohamed et al., 2016) daily available, and environment friendly renewable energy source. All PV modules provided in markets gives 12 or $24 \mathrm{~V}$ (2 up to 5 A). S.Sheik and Devaraj (2014) discussed PV characteristics under different solar irradiance and temperature using currentvoltage (I-V) and power-voltage (P-V) curves. However, the presented results only focus on the output voltage and current without considering the effect of converter on PV parameters. They did not use MPPT but the duty cycle was set manually. Gomathy et al. (2012) discussed the input and output parameters of converter under different solar irradiance, however, their PV voltage changed in similar trends as PV current and power, which is not true based on the theoretical values. In terms of efficiency, (Raj et al., 2020) proposed different types of MPPT DC/DC converters, however, their methods only tested Standard Test Conditions (STC) condition and produced low efficiency with the highest at 93.98\%. The highest efficiency of MPPT DC/ DC converter system found in literature was proposed by Sahu et al. (2016) at $97.54 \%$.

Hence, this research focuses on designing, modeling and simulation of the MPPT DC/ DC boost converter using MATLAB/Simulink software. The block diagram of the system is shown in Figure 1 and the MPPT technique used in this study is IncCond. This study shows the process, step-by-step on how to calculate the converter circuit. Then, the validation of the converter is presented by comparing the $\mathrm{PV}$ parameters obtained from the simulation and theoretical values from I-V and P-V curves under different solar irradiance and temperature. The duty cycle generated by the MPPT algorithm is also presented to confirm the operation of the written algorithm. The output parameters of the converter are also discussed and the efficiency of the system is determined for all cases. 


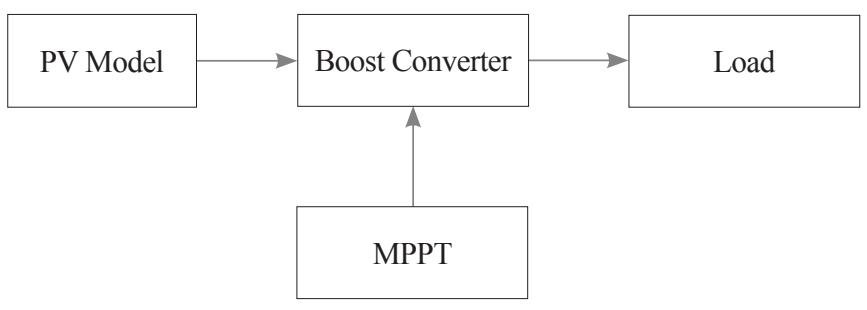

Figure 1: The block diagram of GCPV system

\section{Materials and Methods}

The model of PV and boost converter circuit are shown in Figure 2.

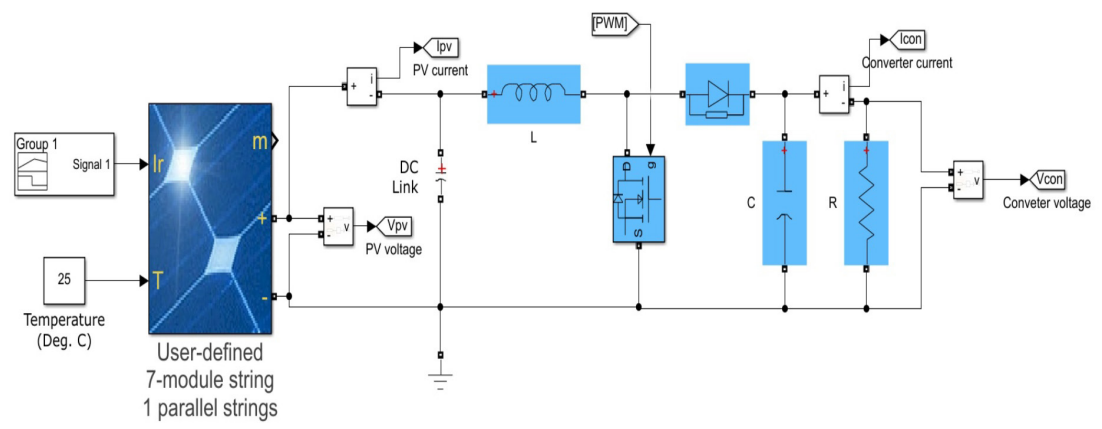

Figure 2: Model of PV and boost converter circuit in MATLAB/simulink

The model is developed in MATLAB/ Simulink. The details of the model are explained as the following:

\section{PV Model}

The specifications of the PV model at STC, with ambient temperature at $25^{\circ} \mathrm{C}$ and the solar irradiance is at $1000 \mathrm{~W} / \mathrm{m}^{2}$ are shown in Table 1 .

Table 1: PV module characteristics at STC for a module

\begin{tabular}{lc}
\hline \multicolumn{1}{c}{ PV Module } & Specifications \\
\hline STC power rating & $260 \mathrm{~W}$ \\
Maximum point voltage, $V_{m p}$ & $31.1 \mathrm{~V}$ \\
Short circuit current, $I_{s c}$ & $8.98 \mathrm{~A}$ \\
Maximum point current, $I_{m p}$ & $8.37 \mathrm{~A}$ \\
Open circuit voltage, $V_{o c}$ & $38.1 \mathrm{~V}$ \\
\hline
\end{tabular}

The proposed PV model consists of seven modules of $260 \mathrm{~W}$. Figure 3 below shows the graph of current versus voltage, or known as $\mathrm{I}-\mathrm{V}$ curve for the modules used in the model. Since the seven modules are connected in series, the PV voltage increased and the PV current is maintained. In Figure 3, a new $V_{o c}$ of seven modules is $266.7 \mathrm{~V}$, obtained by multiplying the correponding voltage for a single module by seven. By varying solar irradiance, the current produced by PV vary accordingly. The lower the solar irradiance, the lower the PV current generated. However, the $V_{o c}$ is almost constant as the temperature is maintained at $25^{\circ} \mathrm{C}$ and is not affected by the change in solar irradiance. The power versus voltage, or known as P-V curve is also shown. Maximum power point obtained from seven modules is $1822 \mathrm{~W}$ at $217.7 \mathrm{~V}$ for STC. Similarly, it can be clearly seen that the changing in solar irradiance changes the maximum power point accordingly, but the voltages are almost constant. 


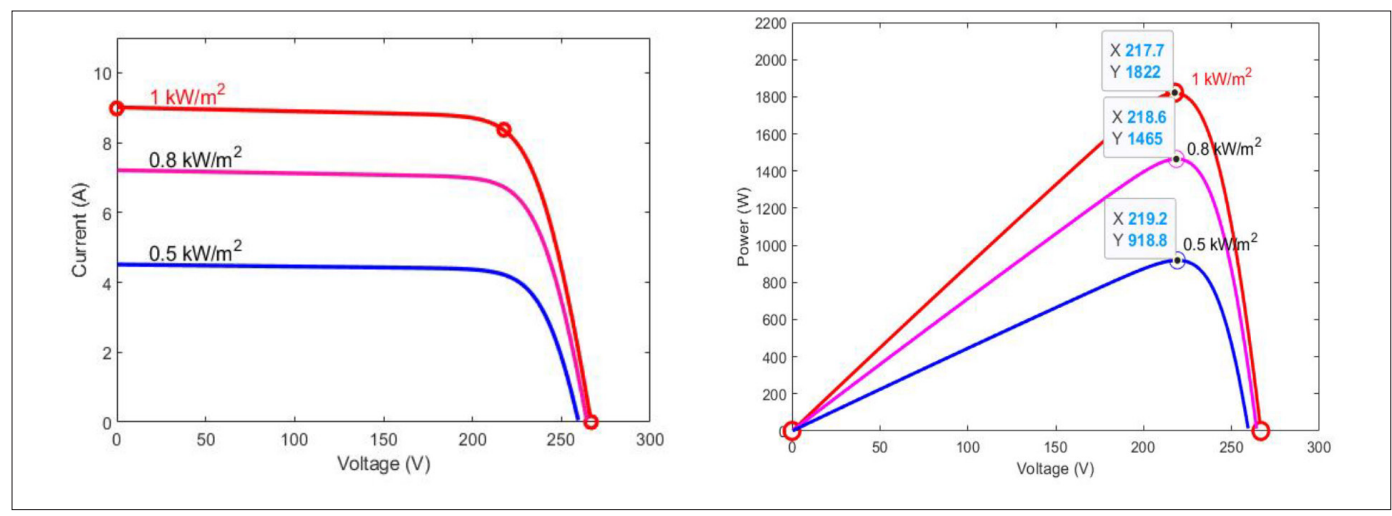

Figure 3: I-V and P-V curves of seven modules PV model under different solar irradiance

The I-V and P-V curves under different temperatures at a constant solar irradiance $1000 \mathrm{~W} / \mathrm{m}^{2}$ are plotted in Figure 4 and it can be clearly observed that varying the temperature changes the and maintains the current produced by solar panel. From the P-V curve, the higher the temperature, the lower the maximum power point.

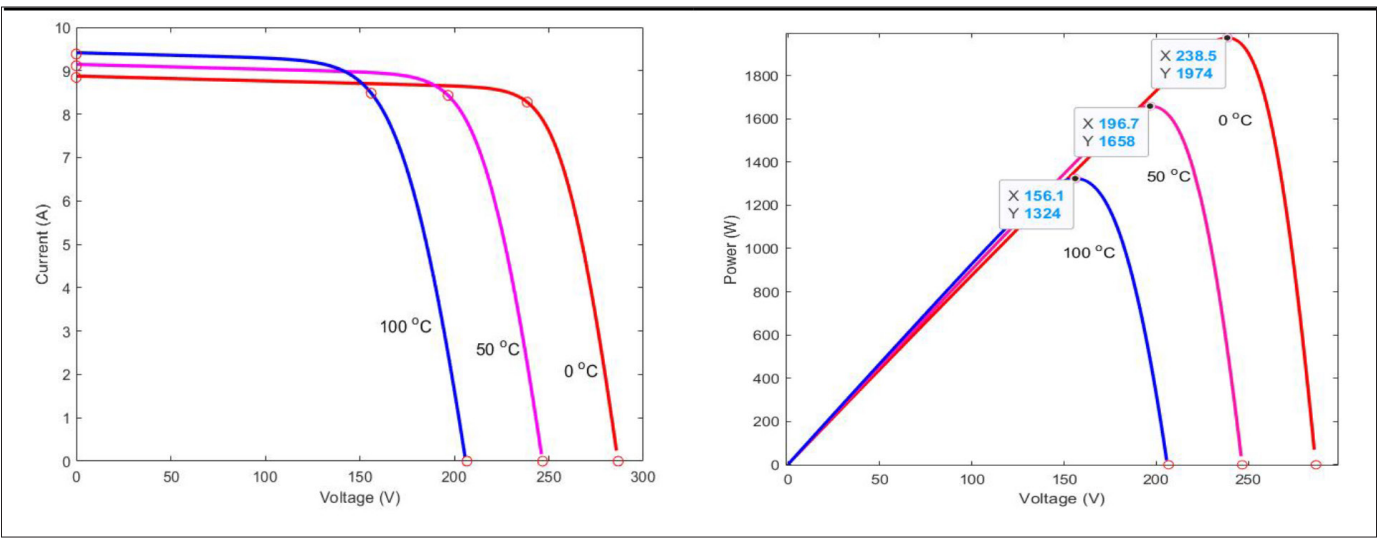

Figure 4: I-V and P-V curves of seven modules PV model under different temperatures

\section{Develop Boost Converter Model}

To design a boost converter for this PV system, the value of duty cycle, $\mathrm{D}$ is calculated using equation (1).

$D=1-\frac{V_{I N}}{V_{\text {OUT }}}$

Since PV output is connected directly to the converter input, and this design considers at STC, then $V_{I N}=V_{m p}=217.7 \mathrm{~V}$ and $V_{\text {OUT }}$ is a desired output voltage that is set at $500 \mathrm{~V}$, then $D$ can be obtained as 0.5646 . Then the suitable load, $R$ can be computed from Ohm's Law, $V_{\text {OUT }}$ $=I_{\text {OUT }} R$ by assuming the converter is ideal as in equation (2).

$$
P_{I N}=P_{\text {OUT }}=V_{I N} I_{I N}=V_{\text {OUT }} I_{\text {OUT }}
$$

$R$ in this case is equal to $137.2 \Omega$. To find the inductance value $L$, the following equation can be used:

$$
L=\frac{V_{I N} \times D}{\Delta I_{L} \times f_{s}}
$$

where $f_{s}=$ switching frequency, $\Delta I_{L}=$ inductor current ripple. The inductor ripple current 
is normally set between $25 \%$ to $40 \%$ of root mean square (RMS) input current. In this study, the ripple current is set at $30 \%$ of $I_{I N}$ which is equal to $2.511 \mathrm{~A}$. Then, the $L$ can be computed from equation (3) and the value is $1.958 \mathrm{mH}$, considering the switching frequency is equal to $25 \mathrm{kHz}$.

To compute the value of the boost converter, the following equation is used:

$$
C=\frac{V_{\text {OUT }} \times D}{2 \times R \times f_{s} \times \Delta V_{\text {OUT }}}
$$

where $\Delta V_{\text {OUT }}$ is output voltage ripple, that has taken $5 \%$ of $\Delta V_{\text {OUT }}$, which is $25 \mathrm{~V}$. The calculated value of $C$ is $1.646 \mathrm{uF}$. It is also noted that the value of DC link capacitor is set at $0.5 \mathrm{mF}$. This value is obtained by trial and error method where it can be seen that the higher the value of the capacitor, the longer is the time taken by the capacitor to reach the $V_{O C}$ based on equation (5). By trial and error with simulation time, $t$, the suitable value of the capacitor can be obtained.

$$
I_{P V}=C_{d c \text { link }} \frac{d V_{P V}}{d t}
$$

\section{MPPT Model}

From I-V curve in Figure 3, the current of PV panel is almost constant for certain range and drops drastically at one point to zero. In other words, as $P=I V$, the higher the $I$ or the $V$, the higher the $P$. However, as can be observed from $\mathrm{P}-\mathrm{V}$ curve of Figure 3, the $P$ increases as the $V$ increases during constant $I$, and after maximum point of $P$, the $P$ drops as the $I$ drops to zero. To ensure the PV output constantly produce maximum power, the switching of boost converter must be controlled at pulse width modulation (PWM) using MPPT technique. The algorithm of IncCond method is written in MALTAB Function with the inputs are PV voltage and current and the output is a duty cycle as illustrated in Figure 5. The details of the algorithm can be found in (Gomathy et al., 2012).

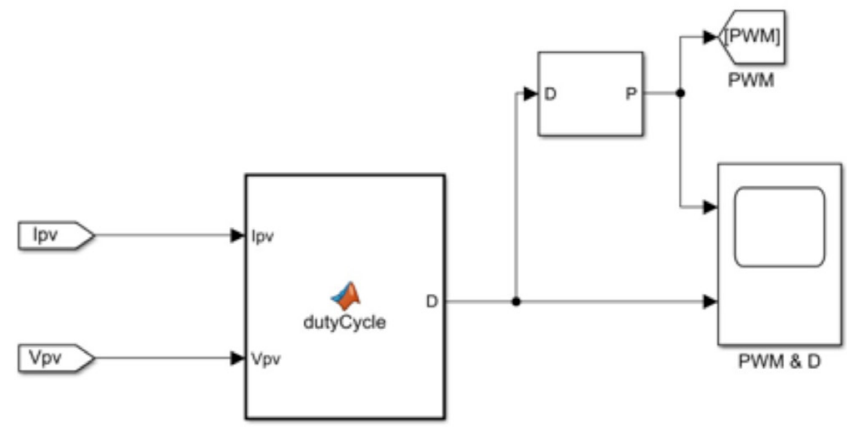

Figure 5: The simulink model of IncCond method

\section{Results and Discussion}

This section is divided into two subsections which are the results before and after the MPPT technique is applied to the system. Without MPPT algorithm, the duty cycle of boost converter is changed manually, meanwhile using the MPPT technique, the value of duty cycle is generated by the MPPT to be applied on MOSFET to ensure the PV power is always maximum at different solar irradiance.

\section{Performance of the DC/DC Converter without MPPT}

Before the boost converter is connected to MPPT block, the PWM of the converter is connected to pulse generator and its duty cycle, $D$ is changed manually. For this case, the solar irradiance is set at STC condition. The results show input and output power of boost converter at $D=0.3$, $D=0.6$ and $D=0.8$ in Figure 6 to Figure 8 , respectively. 
From Figure 6, it can be seen that when the duty cycle is set lower $(D=0.3)$ than the ideal calculated $D=0.5646$, the output PV produced is $1216 \mathrm{~W}$ and the RMS power output boost converter is $1134 \mathrm{~W}$. When the duty cycle is set higher $(D=0.6)$ than the calculated duty cycle, it is found that the output PV is $1423 \mathrm{~W}$ and output boost converter is $1319 \mathrm{~W}$. The output of boost converter is worse when the duty cycle is further increased at $D=0.8$ where the output power boost converter drops to $159.9 \mathrm{~W}$ and PV output power is $181 \mathrm{~W}$. For all selected duty cycle, the $\mathrm{PV}$ power produced is not at maximum point as referred to Figure 3.
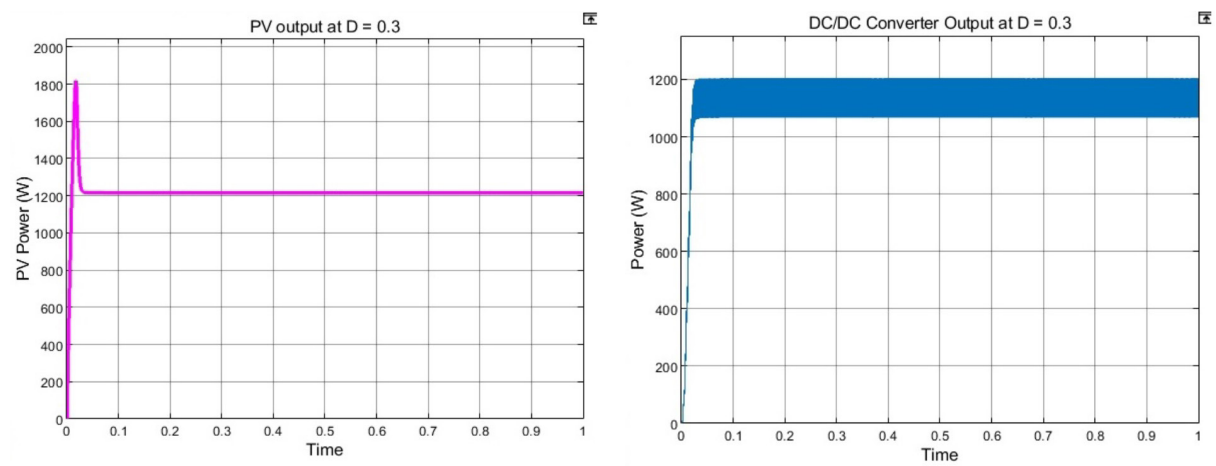

Figure 6: Input and output power of boost converter at $D=0.3$
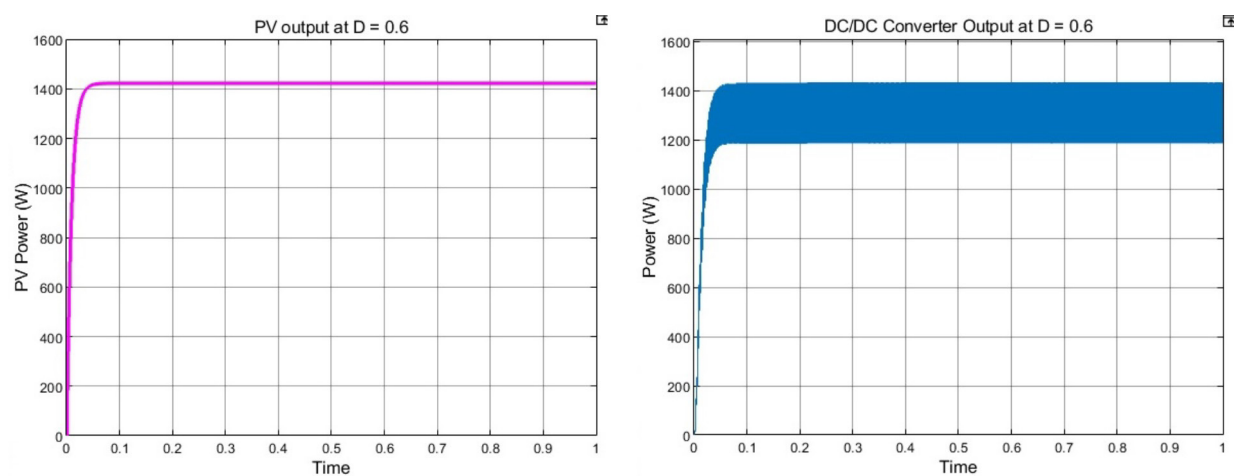

Figure 7: Input and output power of boost converter at $D=0.6$
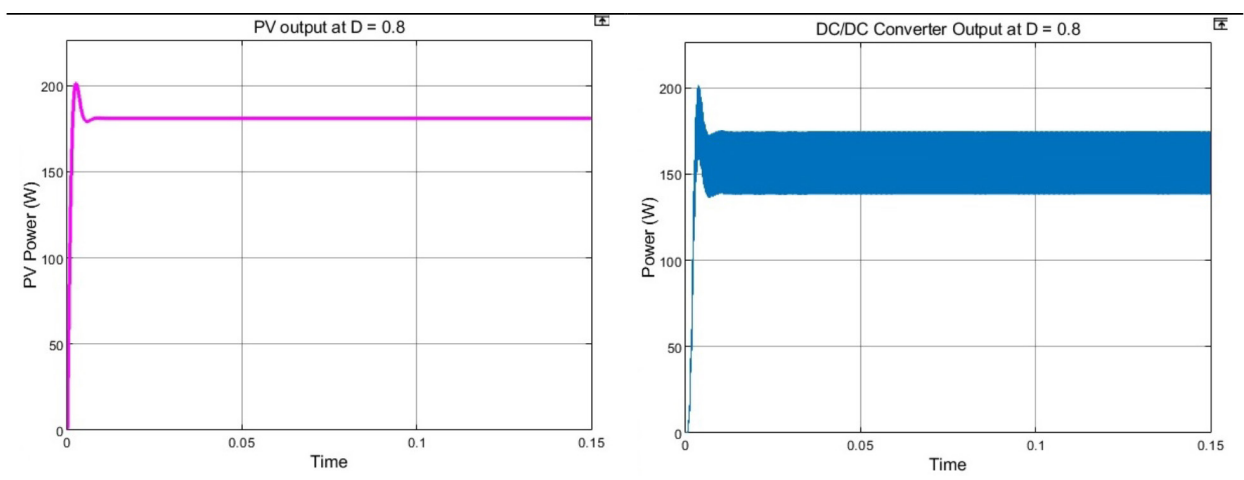

Figure 8: Input and output power of boost converter at $D=0.8$ 
The full parameters of input and output boost converters for different values of duty cycle are written in Table 2 for comparison.
From all the three values of duty cycle, $D=0.6$ has the best tolerance to the ripple voltage since it produces the highest output voltage and the ripple is $5 \%$.

Table 2: Input and output power of boost converters for different duty cycle

\begin{tabular}{ccccccc}
\hline \multirow{2}{*}{ Duty Cycle } & \multicolumn{2}{c}{ Input Boost Converter (PV Output) } & \multicolumn{3}{c}{ Output Boost Converter } \\
\cline { 2 - 7 } & Power (W) & Voltage (V) & Current (A) & Power (W) & Voltage (V) & Current (A) \\
\hline 0.3 & 1216 & 247.7 & 4.910 & 1134 & 394.0 & 2.876 \\
0.6 & 1423 & 161.2 & 8.828 & 1319 & 424.8 & 3.1 .1 \\
0.8 & 181 & 20.14 & 8.988 & 159.9 & 147.8 & 1.079 \\
\hline
\end{tabular}

\section{Performance of the MPPT DC/DC Boost Converter}

The results presented in this section were obtained when the duty cycle produced by MPPT model is connected to PWM of boost converter. It is found that the PV output power is maximum at $1819 \mathrm{~W}$ as in Figure 9, voltage and current are $217.7 \mathrm{~V}$ and $8.354 \mathrm{~A}$, respectively. The required boost converter output voltage considered in calculation is $500 \mathrm{~V}$, however simulation shows that the measured output voltage is $484 \mathrm{~V}$. The output power of boost converter is $1814 \mathrm{~W}$, thus the efficiency of the boost converter is $99.7 \%$. The current flow out of the converter is $3.533 \mathrm{~A}$. Comparing the values of input and output power of converter with and without MPPT as in Table 2 , the maximum power is obtained when the boost converter is connected to MPPT.
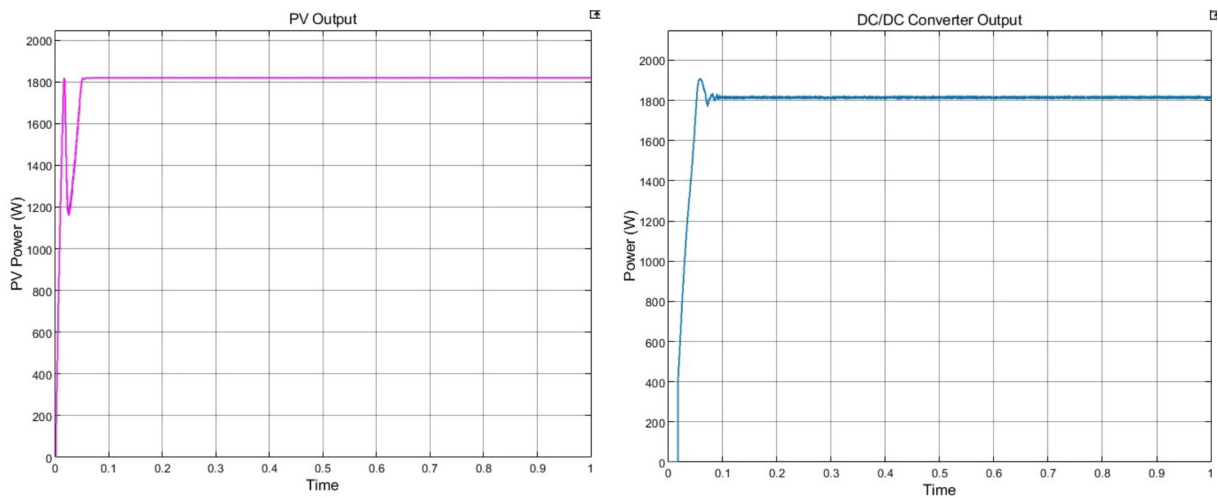

Figure 9: Input and output power of MPPT DC/DC boost converter

From the measured voltage of input and output boost converter, the actual duty cycle produced by MPPT model can be calculated using equation (1) and the value is 0.55 , almost similar to the ideal calculated duty cycle $D$ $=0.5646$. The duty cycle generated by MPPT and the corresponding PWM signal are shown in Figure 10. From the figure, it can be seen that the MPPT keep changing the duty cycle around 0.575 during steady state to maintain the value at maximum power point. In other words, the MPPT model in this study is successful in controlling the PV modules to produce maximum power. 

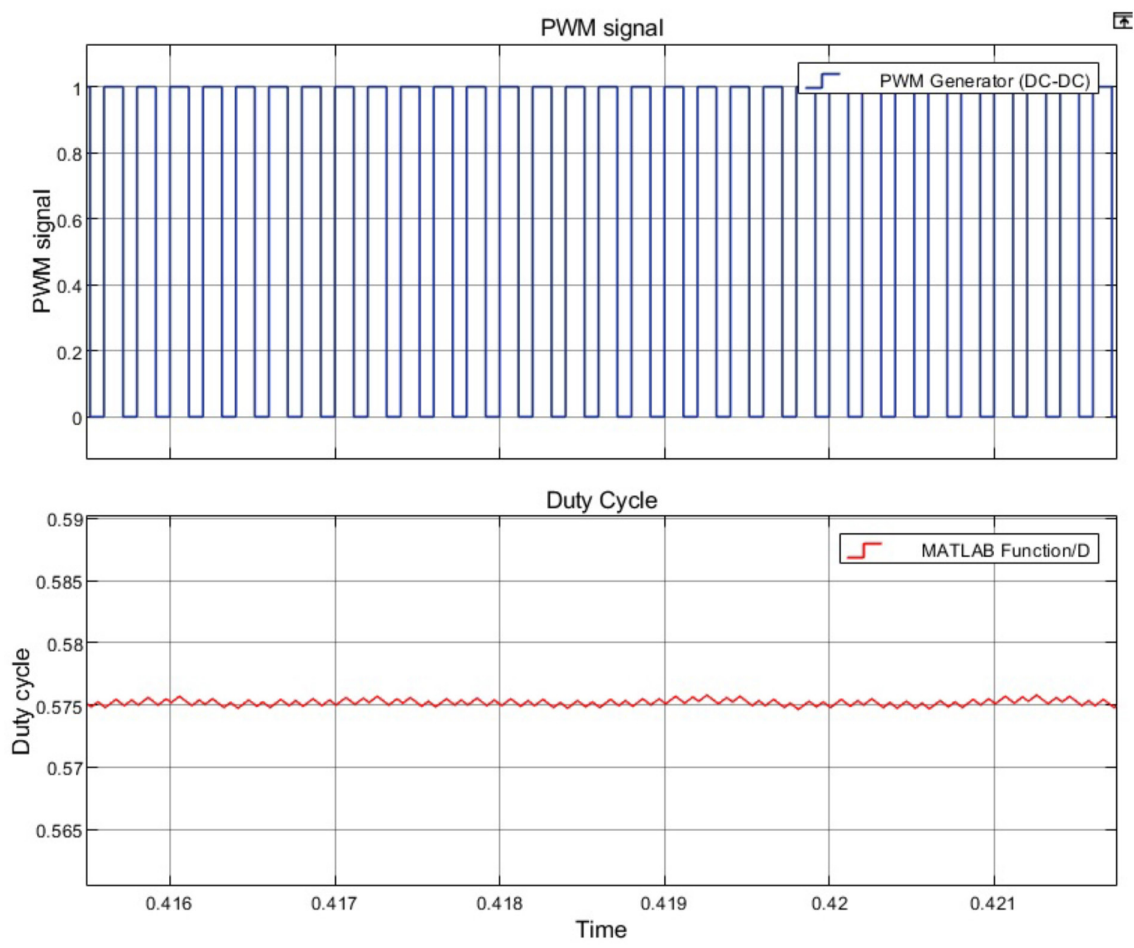

Figure 10: Duty cycle generated by MPPT and the corresponding PWM signal

The MPPT boost converter was also tested with three different values of solar irradiance as depicted in Figure 11 at 1000, 500 and 800 $\mathrm{W} / \mathrm{m}^{2}$. Different solar irradiance is set in signal builder as input to solar PV modules at constant temperature $\mathrm{T}=25^{\circ} \mathrm{C}$. From the figure, it can be seen that the PV voltage is almost constant for different values of solar irradiance. However, the measured value is slightly different as stated in the figure. Small ripple occurs during transition where a little drop is found at $1 \mathrm{~s}$ during a drastic change of solar irradiance from high to low and a small increase during a sudden change from low to high. The PV current and power follow the shape of solar irradiance and the values are as stated. Comparing the value of maximum power obtained from simulation and theoretical values in P-V curve of Figure 3, it is found that the results are validated successfully. 

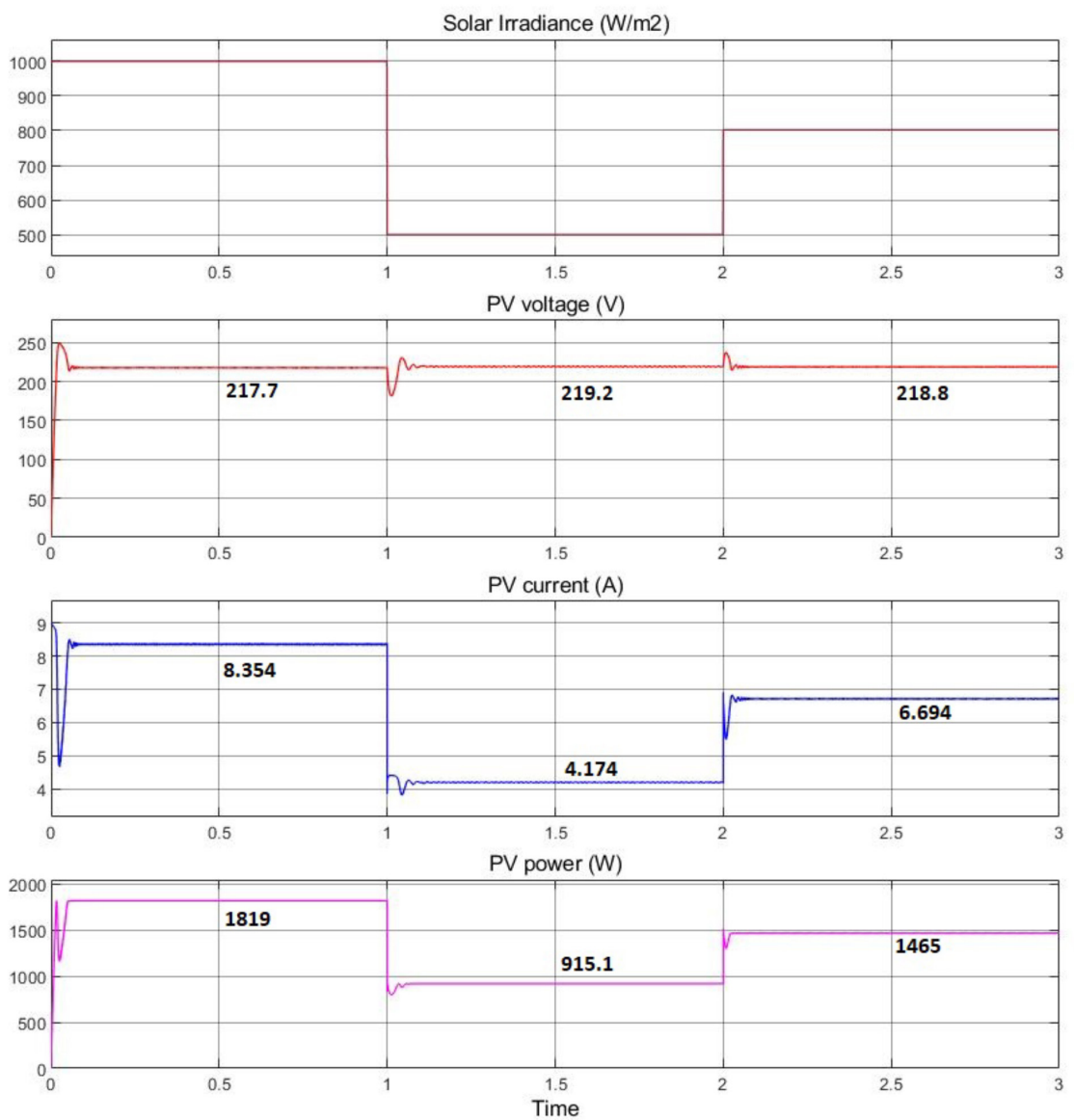

Figure 11: Input boost converter for different solar irradiance

Figure 12 shows the output converter is found that the lowest efficiency of converter parameters for different solar irradiance. From occurs at solar irradiance $800 \mathrm{~W} / \mathrm{m}^{2}$ at $99.4 \%$ the power delivered to the output of converter, it and $99.7 \%$ at the other two conditions. 

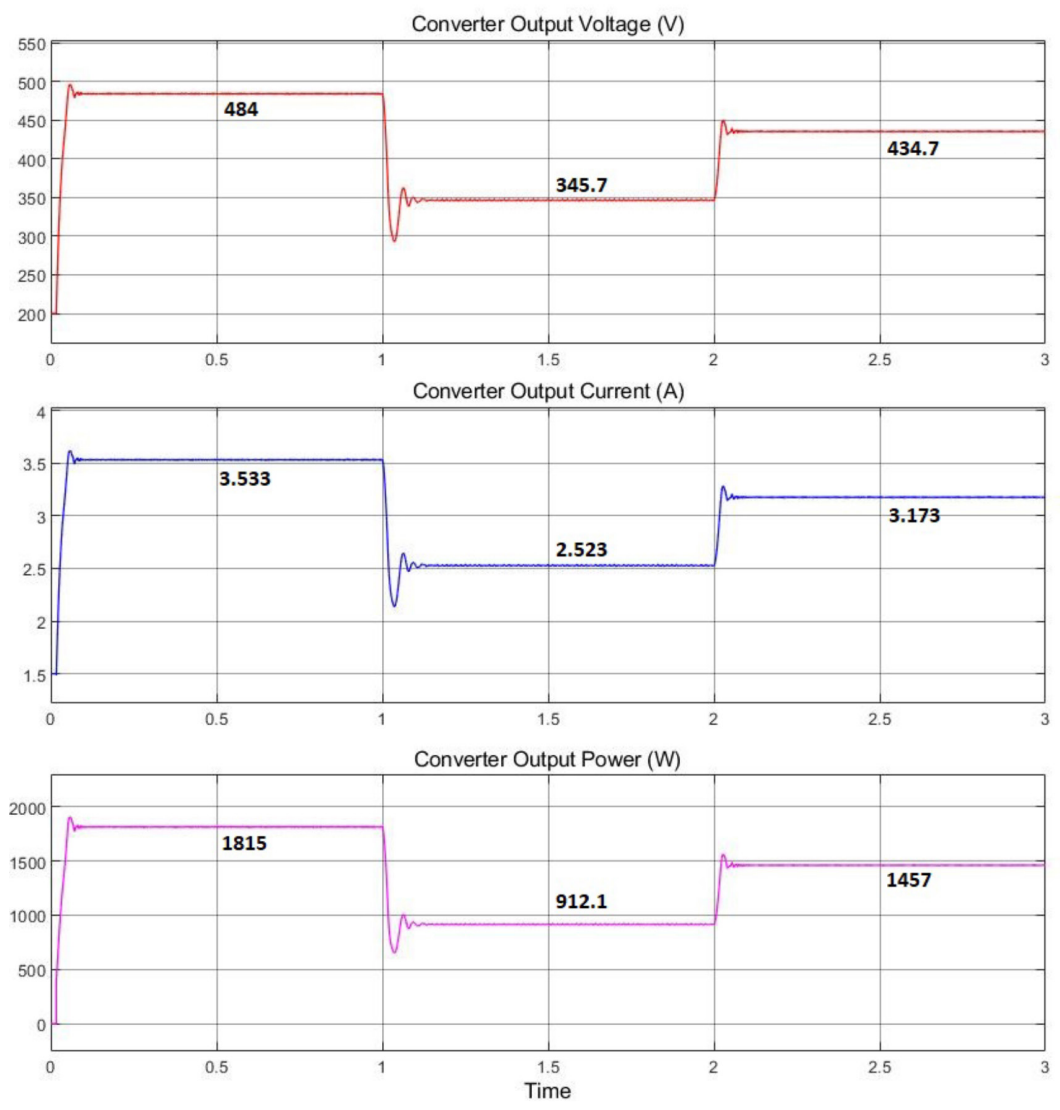

Figure 12: Output boost converter under different solar irradiance

Figure 13 shows the input parameters at three different temperatures. For this case, the current is almost constant at around $8 \mathrm{~A}$, but the changes in voltage and power show the inverse of temperature. Comparing the simulation results and theoretical values in Figure 4, the results are validated correctly. Figure 14 shows the parameter for output converters. From the output power, the efficiency of the converter is high for all temperature which is at $99.7 \%$. 

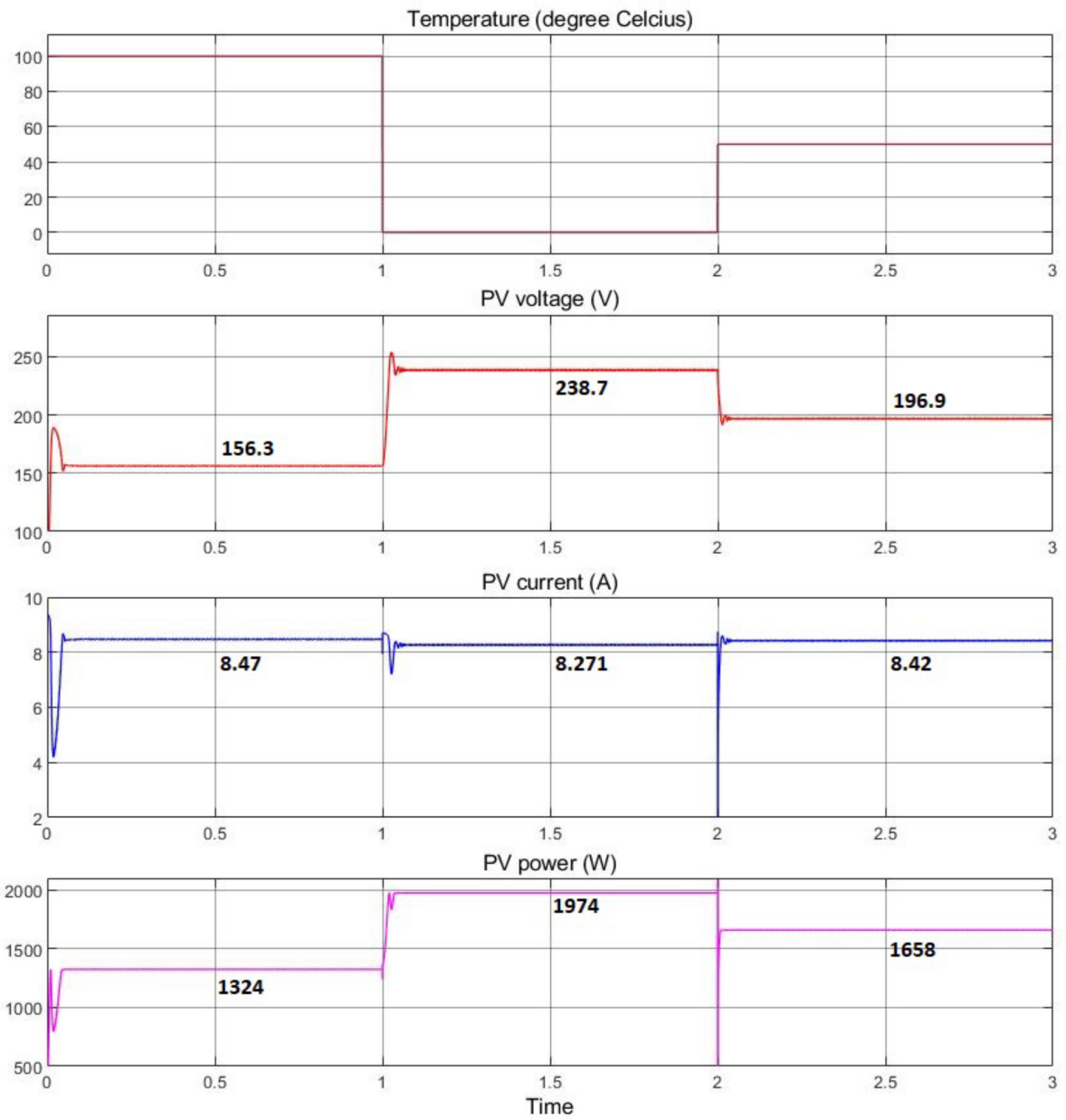

Figure 13: Input boost converter under different temperature 

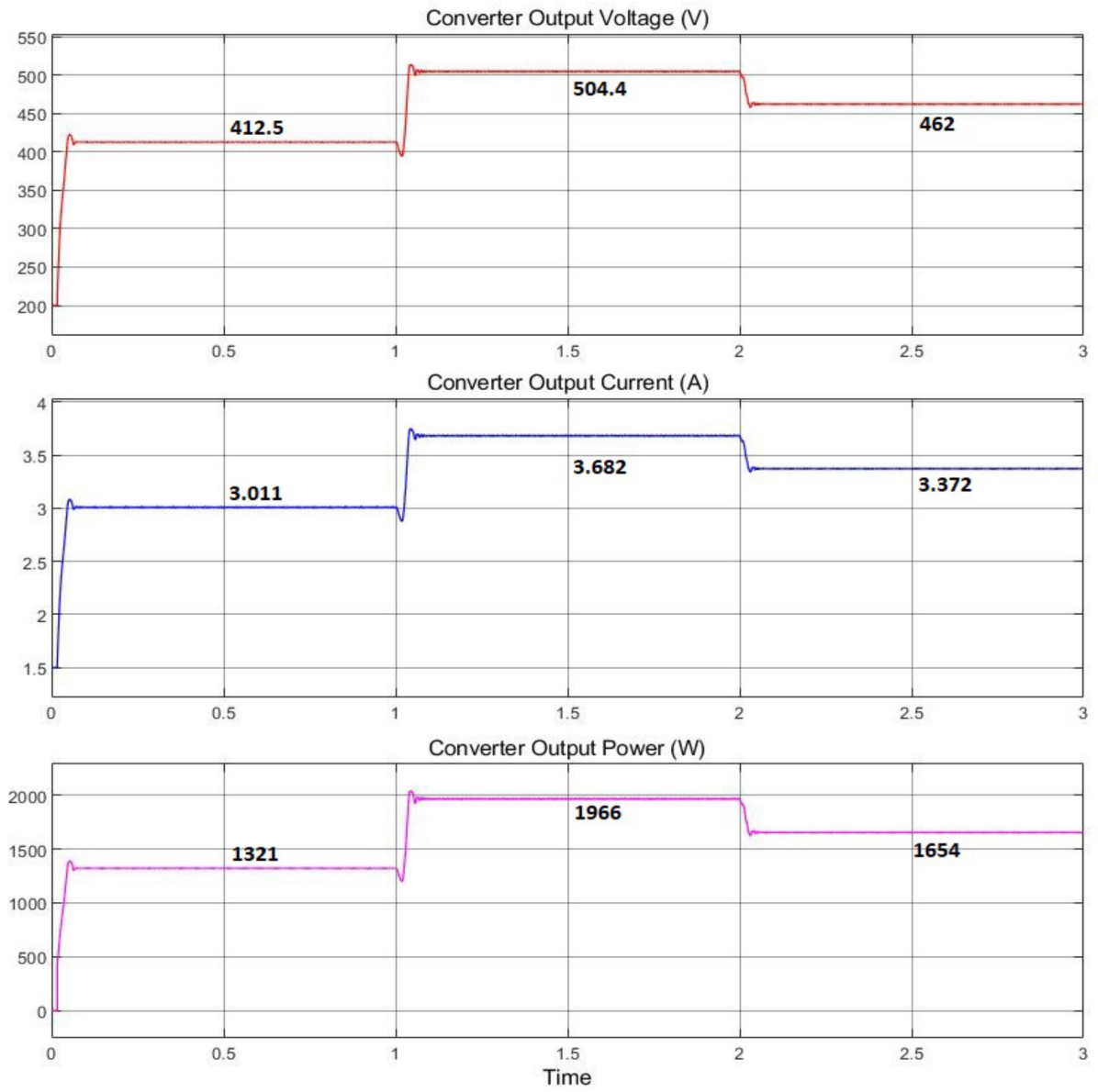

Figure 14: Output boost converter for different temperatures

The duty cycle generated by the MPPT block for three different solar irradiance and temperature are shown in Figure 15 in which the duty cycle takes small time at transient state to adjust to the best duty cycle before maintaining

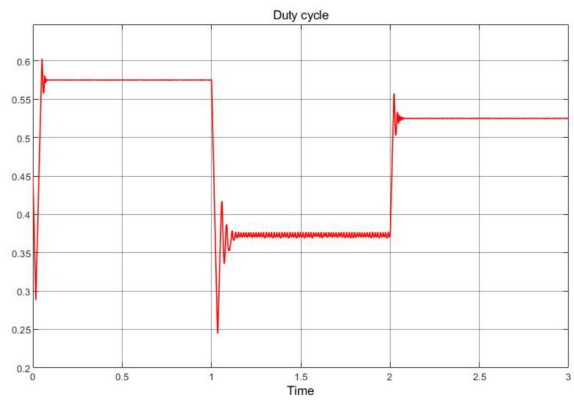

it during the steady state at $0.575,0.3713$ and 0.5251 for the corresponding solar irradiance, and at $0.65,0.55$ and 0.6 for the corresponding temperature. It shows the MPPT algorithm is successfully functioning.

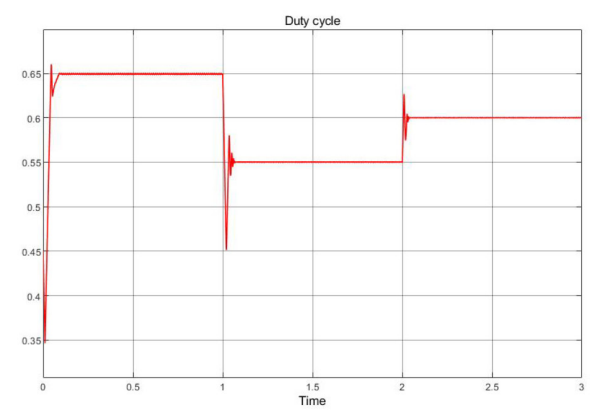

Figure 15: The duty cycle for different solar irradiance and temperature 


\section{Conclusion}

A MPPT DC/DC boost converter for $1.8 \mathrm{~kW} \mathrm{PV}$ modules is successfully modeled and simulated. The input parameters have been validated using $\mathrm{I}-\mathrm{V}$ and $\mathrm{P}-\mathrm{V}$ curves for different solar irradiance and temperature. From the output parameters, the efficiency of the converter is $99.7 \%$ for almost all conditions. The generated duty cycle from MPPT algorithm shows that it works as it is supposed to be, i.e. extract and maintain the maximum power point from PV modules.

\section{Acknowledgements}

The authors would like to express their gratitude to the Ministry of Higher Education Malaysia for sponsoring this work under Fundamental Research Grant Scheme (FRGS/1/2018/TK07/ $\mathrm{UMT} / 02 / 1)$.

\section{References}

Ahmed, J., \& Salam, Z. (2015). An improved perturb and observe (P\&O) maximum power point tracking (MPPT) algorithm for higher efficiency. Applied Energy, 150, 97-108. https://doi.org/10.1016/j. apenergy.2015.04.006

Al-Shamani, A. N., Sopian, K., Mat, S., \& Abed, A. M. (2017). Performance enhancement of photovoltaic grid-connected system using PVT panels with nanofluid. Solar Energy, 150, 38-48. https://doi.org/10.1016/j. solener.2017.04.005

Al-Waeli, A. H. A., Sopian, K., Kazem, H. A., \& Chaichan, M. T. (2018). Nanofluid based grid connected PV/T systems in Malaysia: A techno-economical assessment. Sustainable Energy Technologies and Assessments, 28(June), 81-95. https://doi.org/10.1016/j. seta.2018.06.017

Alik, R., \& Jusoh, A. (2018). An enhanced $\mathrm{P} \& \mathrm{O}$ checking algorithm MPPT for high tracking efficiency of partially shaded PV module. Solar Energy, 163 (December 2017), 570-580. https://doi.org/10.1016/j. solener.2017.12.050
Bellia, H., Youcef, R., \& Fatima, M. (2014). A detailed modeling of photovoltaic module using MATLAB. NRIAG Journal of Astronomy and Geophysics, 3(1), 53-61. https://doi.org/10.1016/j.nrjag.2014.04.001

Ghafoor, A., \& Munir, A. (2015). Design and economics analysis of an off-grid PV system for household electrification. Renewable and Sustainable Energy Reviews, 42, 496-502. https://doi.org/10.1016/j. rser.2014.10.012

Gomathy, S., Saravanan, S., \& Thangavel, S. (2012). Design and Implementation of Maximum Power Point Tracking ( MPPT ). Algorithm for a Standalone PV System. 3(3), 1-7.

Huang, L., Qiu, D., Xie, F., Chen, Y., \& Zhang, B. (2017). Modeling and stability analysis of a single-phase two-stage grid-connected photovoltaic system. Energies, 10(12). https://doi.org/10.3390/en10122176

Jain, K., Gupta, M., \& Kumar Bohre, A. (2018). Implementation and Comparative Analysis of PO and INC MPPT Method for PV System. India International Conference on Power Electronics, IICPE, 2018-Decem, 1-6. https://doi.org/10.1109/ IICPE.2018.8709519

Krismadinata, Rahim, N. A., Ping, H. W., \& Selvaraj, J. (2013). Photovoltaic Module Modeling using Simulink/Matlab. Procedia Environmental Sciences, 17, 537-546. https://doi.org/10.1016/j. proenv.2013.02.069

Kusch-Brandt. (2019). Urban Renewable Energy on the Upswing: A Spotlight on Renewable Energy in Cities in REN21's "Renewables 2019 Global Status Report." In Resources (Vol. 8, Issue 3). https://doi. org/10.3390/resources 8030139

Loukriz, A., Haddadi, M., \& Messalti, S. (2016). Simulation and experimental design of a new advanced variable step size Incremental Conductance MPPT algorithm for PV systems. ISA Transactions, 62, 30-38. https://doi.org/10.1016/j.isatra.2015.08.006 
Mohamed, H. A., Khattab, H. A., Mobarka, A., \& Morsy, G. A. (2016). Design, control and performance analysis of DC-DC boost converter for stand-alone PV system. 2016 18th International Middle-East Power Systems Conference, MEPCON 2016 - Proceedings, 101-106. https://doi. org/10.1109/MEPCON.2016.7836878

Raj, A., Arya, S. R., \& Gupta, J. (2020). Solar PV array-based DC-DC converter with MPPT for low power applications. Renewable Energy Focus, 34(September), 109-119. https://doi.org/10.1016/j.ref.2020.05.003
S.Sheik, M., \& Devaraj, D. (2014). Simulation and Analysis of Stand-alone Photovoltaic System with Boost Converter using MATLAB/Simulink. IEE International Conference on Circuit, Power and Computing Technologies, 814-821.

Sahu, P., Verma, D., \& Nema, S. (2016). Physical Design and Modelling of Boost Converter systems. 2016 International Conference on Electrical Power and Energy Systems (ICEPES), 10-15.

Tey, K. S., \& Mekhilef, S. (2014). Modified incremental conductance MPPT algorithm to mitigate inaccurate responses under fast-changing solar irradiation level. Solar Energy, 101, 333-342. https://doi. org/10.1016/j.solener.2014.01.003 